\title{
Zinc depletion regulates the processing and secretion of IL-1及
}

\author{
H Summersgill ${ }^{1,4}$, H England $^{1,4}$, G Lopez-Castejon ${ }^{1}$, CB Lawrence ${ }^{1}$, NM Luheshi ${ }^{1,2}$, J Pahle $^{3}$, P Mendes ${ }^{3}$ and D Brough ${ }^{*, 1}$
}

Sterile inflammation contributes to many common and serious human diseases. The pro-inflammatory cytokine interleukin- $1 \beta$ (IL-1 $\beta$ ) drives sterile inflammatory responses and is thus a very attractive therapeutic target. Activation of IL-1 $\beta$ in sterile diseases commonly requires an intracellular multi-protein complex called the NLRP3 (NACHT, LRR, and PYD domainscontaining protein 3) inflammasome. A number of disease-associated danger molecules are known to activate the NLRP3 inflammasome. We show here that depletion of zinc from macrophages, a paradigm for zinc deficiency, also activates the NLRP3 inflammasome and induces IL-1 $\beta$ secretion. Our data suggest that zinc depletion damages the integrity of lysosomes and that this event is important for NLRP3 activation. These data provide new mechanistic insight to how zinc deficiency contributes to inflammation and further unravel the mechanisms of NLRP3 inflammasome activation.

Cell Death and Disease (2014) 5, e1040; doi:10.1038/cddis.2013.547; published online 30 January 2013

Subject Category: Immunity

Inflammation is a protective host response required for resistance to infection. However, inflammation that occurs in response to tissue injury in the absence of pathogen is considered sterile, and can contribute to damage. ${ }^{1}$ Sterile inflammation is driven by the pro-inflammatory cytokines of the interleukin-1 (IL-1) family. ${ }^{1} \mathrm{IL}-1 \beta$ is a master cytokine central to the damaging inflammatory response in a range of major human diseases. ${ }^{2}$ For this reason, understanding the mechanisms of IL- $1 \beta$ production is a crucial area of research that may lead to the identification of new therapeutic targets and therapies. IL- $1 \beta$ is produced by macrophages as a $31-\mathrm{kDa}$ precursor called pro-IL-1 $\beta$. Pro-IL-1 $\beta$ is expressed in response to pathogen-associated molecular patterns or damage-associated molecular patterns (DAMPs) that bind to pattern recognition receptors (PRRs) on the macrophage to upregulate pro-inflammatory gene expression. ${ }^{3,4}$ Pro-IL- $1 \beta$ is inactive and remains intracellular until a further pathogenassociated molecular pattern or DAMP stimulation activates cytosolic PRRs, often of the NOD-like receptor family, to form large multi-protein complexes called inflammasomes. ${ }^{5}$ These complexes consist of the PRR, pro-caspase-1, and depending upon the PRR, an adaptor protein called ASC (apoptosisassociated speck-like protein containing a caspase recruitment domain), that interact via homotypic interactions between caspase activation and recruitment and pyrin (PYD) domains. ${ }^{5}$ Of the inflammasomes identified to-date, the best characterised and most relevant to sterile inflammatory responses is formed by the PPR NLRP3 (NACHT, LRR, and PYD domains-containing protein 3). ${ }^{5,6}$ When NLRP3 senses DAMPs it recruits ASC, which in turn recruits caspase- 1 causing its activation. Caspase- 1 then processes pro-IL-1 $\beta$ to a mature form that is rapidly secreted from the cell. ${ }^{5}$

Zinc $\left(\mathrm{Zn}^{2+}\right)$ is an essential nutrient, serving both structural and catalytic cofactor roles for many proteins (up to $10 \%$ of the human proteome binds $\mathrm{Zn}^{2+7}$ ). $\mathrm{Zn}^{2+}$ is also central to many key molecular and cellular reactions critical for innate and adaptive immune system function. ${ }^{8}$ Even though total levels of cellular $\mathrm{Zn}^{2+}$ are high, the levels of available $\mathrm{Zn}^{2+}$ are tightly regulated and the level of available $\mathrm{Zn}^{2+}$ in plasma drops rapidly in response to bacterial endotoxin or cytokines. ${ }^{9,10}$ $\mathrm{Zn}^{2+}$ deficiency is common in older people ${ }^{11}$ and contributes to many clinical disorders, such as growth retardation, immune dysfunction, and cognitive impairment, affecting up to 2 billion people worldwide. ${ }^{12} \mathrm{Zn}^{2+}$ supplementation is reported to be beneficial at ameliorating the effects of these disorders and in many infectious and non-infectious diseases. ${ }^{13,14}$

We reported previously an interaction between $\mathrm{Zn}^{2+}$ and caspase-1-dependent processing and release of $\mathrm{IL}-1 \beta{ }^{15}$ A brief $15 \mathrm{~min}$ incubation of lipopolysacharide (LPS)-primed peritoneal macrophages with the $\mathrm{Zn}^{2+}$ chelator TPEN $(N, N, N, N$ '-Tetrakis-(2-pyridylmethyl) ethylenediamine) inhibits IL-1 $\beta$ release in response to NLRP3 inflammasome agonists

\footnotetext{
${ }^{1}$ Faculty of Life Sciences, University of Manchester, AV Hill Building, Oxford Road, Manchester, UK; ${ }^{2}$ Medlmmune Ltd, Aaron Klug Building, Granta Park, Cambridge, UK and ${ }^{3}$ School of Computer Science, University of Manchester, Manchester, UK

${ }^{*}$ Corresponding author: D Brough, Faculty of Life Sciences, University of Manchester, 2.003 AV Hill Building, Oxford Road, Manchester M13 9PT, UK. Tel: +44 0161275 5039; Fax: +44 0161275 5948; Email: david.brough@manchester.ac.uk

${ }^{4}$ These authors contributed equally to this work.

Keywords: inflammation; caspase-1; interleukin-1; inflammasome; zinc

Abbreviations: $\mathrm{A} \beta$, Amyloid beta; ASC, apoptosis-associated speck-like protein containing a caspase recruitment domain; CA, calyculin A; DAMPs, damageassociated molecular patterns; DMSO, dimethyl sulfoxide; DTPA, diethylenetriaminepentaacetic acid; IL, interleukin; LPS, lipopolysaccharide; LDH, lactate dehydrogenase; NLRP3, NACHT, LRR, and PYD domains-containing protein 3; PRRs, pattern recognition receptors; PYD, pyrin domain; ROS, reactive oxygen species; $\mathrm{SIH}$, salicylaldehyde isonicotinoyl hydrazone; TPEN, $N, N, N^{\prime}, N^{\prime}$-tetrakis-(2-pyridylmethyl) ethylenediamine; XIAP, X-linked inhibitor of apoptosis protein

Received 29.8.13; revised 09.12.13; accepted 09.12.13; Edited by T Brunner
} 
ATP and nigericin. ${ }^{15}$ However, here we have discovered that sustained $\mathrm{Zn}^{2+}$ depletion acts as a stimulus for the NLRP3 inflammasome. These data provide valuable insights into regulation of the NLRP3 inflammasome, and the mechanisms through which $\mathrm{Zn}^{2}+$ deficiency may contribute to inflammatory disease.

\section{Results and Discussion}

We have previously reported that brief $(15 \mathrm{~min})$ incubation of LPS-primed mouse peritoneal macrophages with TPEN completely inhibits ATP- and nigericin-induced caspase-1 activation and secretion of $\mathrm{IL}-1 \beta .^{15}$ We discovered that this was probably due to an inhibition of the pannexin-1 hemichannel. To test whether these data are relevant to inflammation in vivo, adult C57BL/6 mice were injected intraperitoneally (i.p.) with LPS $(5 \mathrm{mg} / \mathrm{kg})$ followed by TPEN (1 or $10 \mathrm{mg} / \mathrm{kg}$ ) $1 \mathrm{~h}$ later, with peritoneal lavages recovered $3 \mathrm{~h}$ following TPEN administration. Levels of IL-1 $\beta$ and of another pro-inflammatory cytokine, IL-6, in the lavage fluid were analysed by ELISA. In contrast to our previous in vitro data, ${ }^{15}$ TPEN in vivo was pro-inflammatory, increasing the levels of both IL-1 $\beta$ and IL-6 (Figures $1 \mathrm{a}$ and $\mathrm{b}$ ).

We therefore asked the question whether, in contrast to our report on the effects of short-term TPEN treatment on NLRP3 inflammasome activation, ${ }^{15}$ sustained $\mathrm{Zn}^{2+}$ depletion with TPEN could activate IL-1 $\beta$ processing and release. To test whether sustained $(4 \mathrm{~h}) \mathrm{Zn}^{2+}$ depletion modifies the production and secretion of IL- $1 \beta$ directly, we treated cultured mouse primary peritoneal macrophages with TPEN $(0-10 \mu \mathrm{M})$ or dimethyl sulfoxide (DMSO; $0-0.5 \%$ ) for $4 \mathrm{~h}$ and measured the levels of IL-1 $\beta$ in cell lysates and culture supernatants by ELISA. Under these conditions TPEN did not induce significant expression or release of IL-1 $\beta$ (data not shown). After priming cultured macrophages with LPS $(1 \mu \mathrm{g} / \mathrm{ml}, 2 \mathrm{~h})$, TPEN treatment $(10 \mu \mathrm{M}, 4 \mathrm{~h})$ induced the release of mature (17 kDa) IL-1 $\beta$ (Figure 2aii, iii), and caused cell death (Figure 2ai). This is consistent with models of NLRP3inflammasome-dependent IL-1 $\beta$ secretion where an initial priming stimulus is required to induce the expression of pro-IL$1 \beta$ and the PRR NLRP3. ${ }^{16}$ The effect of TPEN on cell death and IL-1 $\beta$ processing and release was specific to a depletion of $\mathrm{Zn}^{2+}$ as $4 \mathrm{~h}$ incubation with selective copper (TTM, ammonium tetrathiomolybdate) or iron $(\mathrm{SIH}$, salicylaldehyde isonicotinoyl hydrazone) chelators had no effect on either parameter (Figure 2a). The addition of $\mathrm{ZnCl}_{2}(50 \mu \mathrm{M})$ to TPEN-treated LPS-primed macrophage cultures reduced cell death and inhibited $\mathrm{IL}-1 \beta$ release (Figure $2 \mathrm{~b}$ ). Another $\mathrm{Zn}^{2+}$ chelator (DTPA, diethylenetriaminepentaacetic acid ${ }^{17}$ ) also induced the release of IL-1 $\beta$ (Figure $2 \mathrm{c}$ ). We confirmed that the addition of TPEN quenched cellular $\mathrm{Zn}^{2+}$ using the following protocol. LPS-primed $\mathrm{J774}$ macrophages were loaded with the selective $\mathrm{Zn}^{2+}$ indicator FluoZin-3 and a fluorescent lysosomal marker, Lysotracker Red, and were imaged using a BD Pathway Bioimager (San Jose, CA, USA). Addition of $1 \mu \mathrm{M}$ of the $\mathrm{Zn}^{2+}$ ionophore, 1-hydroxypyridine-2thione (zinc salt; ZnPyr) rapidly increased the FlouZin-3 fluorescence in the cells saturating the dye $(<20 \mathrm{~s})$, but had no effect on lysotracker red fluorescence (Figures $2 d$ and e). Addition of TPEN to a $\mathrm{Zn}^{2+}$-loaded cell caused a rapid drop in FluoZin-3 fluorescence confirming the specificity of the response (Figures $2 \mathrm{~d}$ and e). Thus, sustained depletion of $\mathrm{Zn}^{2+}$ was toxic and induced the processing and release of $\mathrm{IL}-1 \beta$ analogous to other known danger signals. The effects of $\mathrm{Zn}^{2+}$ depletion on $\mathrm{IL}-1 \beta$ release described here may help to explain, at least in part, the well-documented contribution of $\mathrm{Zn}^{2+}$ deficiency to inflammation and disease.

To investigate the mechanism through which TPEN induced $\mathrm{IL}-1 \beta$ release, we initially investigated whether release was dependent upon caspase-1 or caspase-8. TPEN induces tumour cell death by causing the degradation of X-linked inhibitor of apoptosis protein (XIAP), ${ }^{18,19}$ and inhibitor of apoptosis protein inhibitors induce IL- $1 \beta$ processing via both NLRP3/caspase-1 and caspase-8-dependent mechanisms. ${ }^{20}$ Once activated caspase- 8 can cleave pro-IL-1 $\beta$ directly at the same site as caspase-1, and induce secretion of the mature form. ${ }^{20,21}$ Cell death can also induce the release of $\mathrm{IL}-1 \beta$ from macrophages that is dependent upon caspase-8, but is independent of inflammasomes. ${ }^{22}$ Thus, we investigated whether TPEN-induced IL-1 $\beta$ processing and secretion were dependent on caspase-1 or caspase-8. Treatment of LPS-primed primary peritoneal macrophages with TPEN resulted in the loss of XIAP and an activation of caspase-8 (Figure 3ai,ii). The extracellular $\mathrm{Zn}^{2+}$ chelator
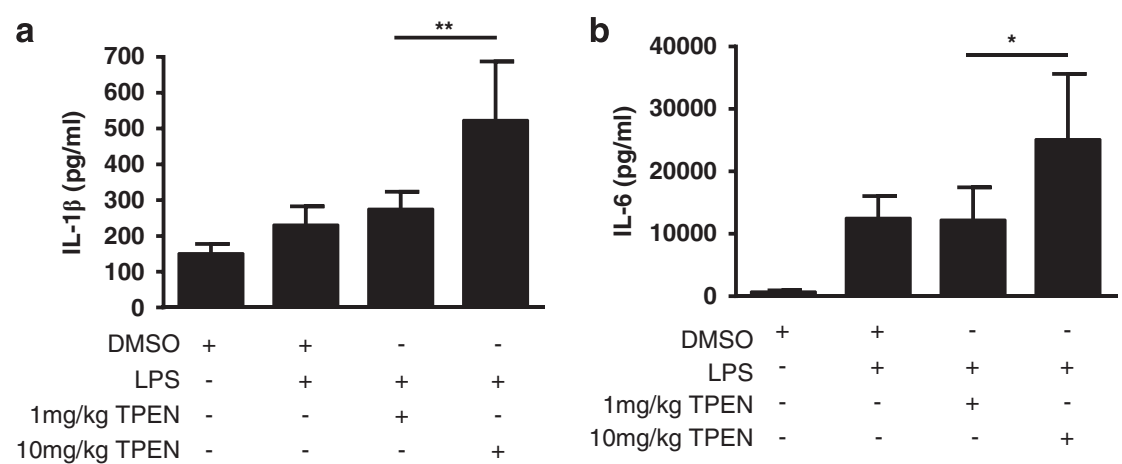

Figure 1 TPEN is pro-inflammatory in vivo. Male C57BL/6 mice were injected i.p. with a septic dose $(5 \mathrm{mg} / \mathrm{kg})$ of LPS. $1 \mathrm{~h}$ after LPS injection the mice received a second injection that was vehicle (10\% DMSO in saline), $1 \mathrm{mg} / \mathrm{kg}$ TPEN, or $10 \mathrm{mg} / \mathrm{kg}$ TPEN. $3 \mathrm{~h}$ after the second injection the animals were anaesthetised, lavage fluid was collected, and analysed for the presence of IL-1 $\beta$ (a) or IL-6 (b) by specific ELISA. Data were collected from six animals per group and are presented as the mean \pm S.D. ${ }^{* \star} P<0.01$, ${ }^{*} P<0.05$ 
a $\mathrm{i}$$$
\text { a }
$$
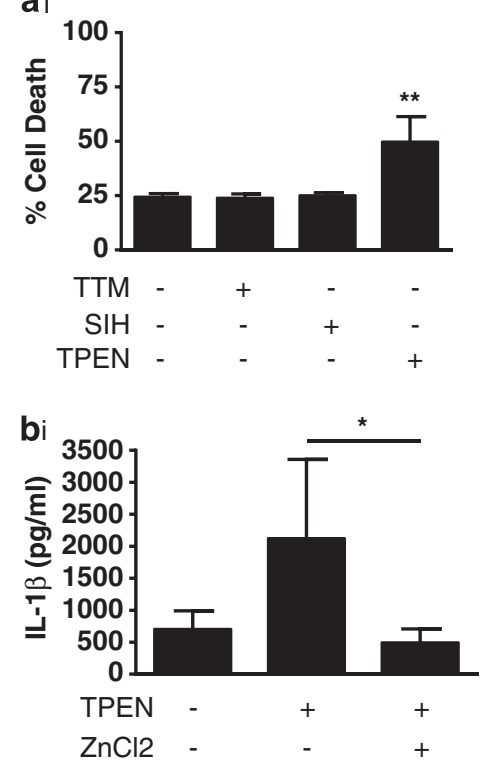

ii
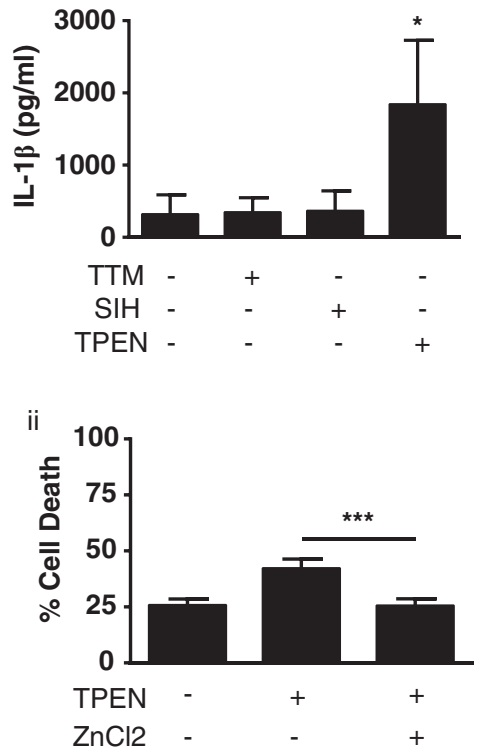
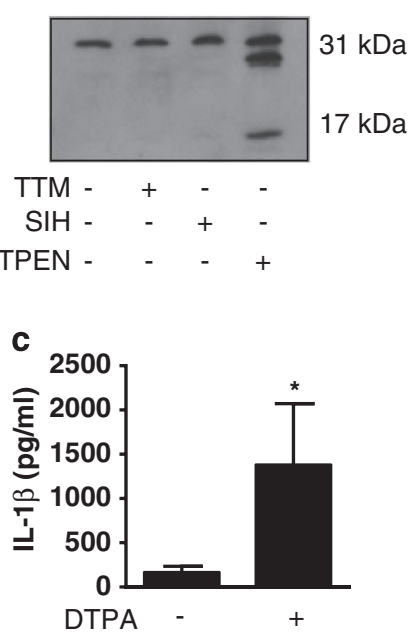

d

FluoZin-3
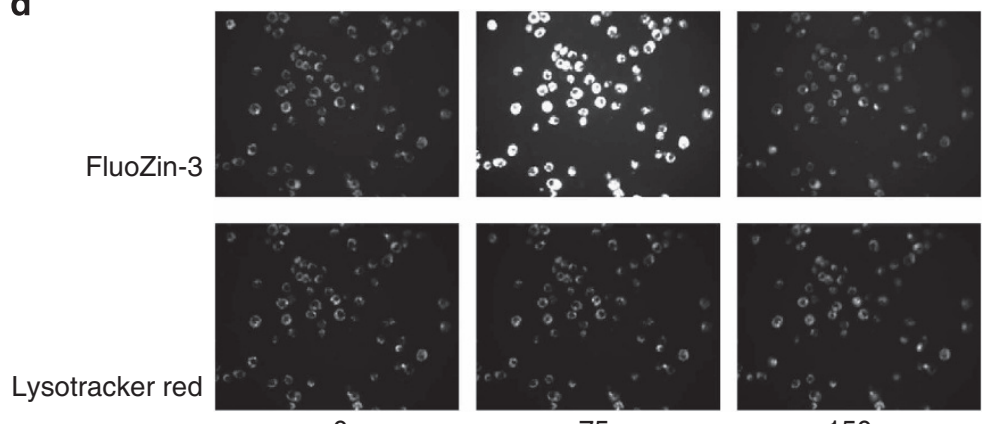

Os

$75 s$

150 s

ei
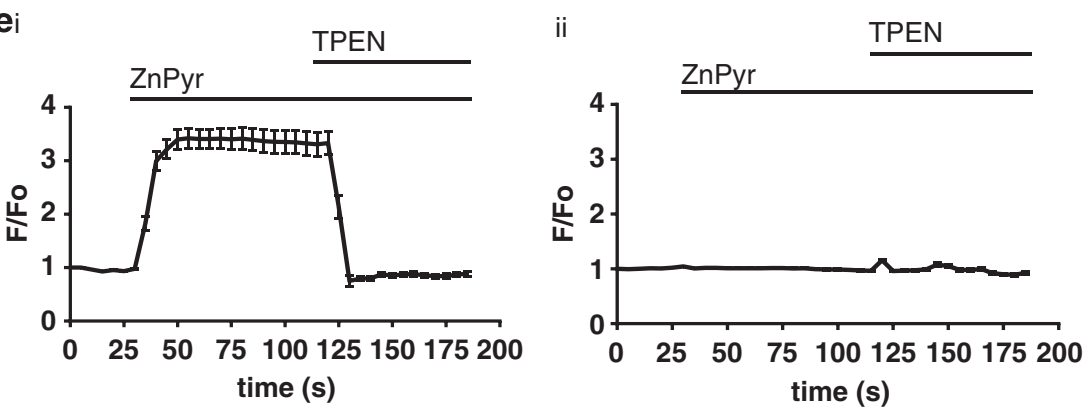

Figure $2 \mathrm{Zn}^{2+}$ depletion drives processing and secretion of IL-1 $\beta$ from macrophages. (a) Mouse primary peritoneal macrophages were primed with LPS (1 $\mu \mathrm{g} / \mathrm{ml}, 2 \mathrm{~h}$ ), followed by $4 \mathrm{~h}$ treatment with $10 \mu \mathrm{M}$ TPEN, the copper chelator TTM, or the iron chelator SIH with effects on cell death measured by LDH release (i), IL-1 $\beta$ release measured by ELISA (ii), and IL- $1 \beta$ processing measured by western blot analysis (iii). The band at $31 \mathrm{kDa}$ is pro-IL-1 $\beta$ and the band at $17 \mathrm{kDa}$ is IL-1 $\beta$. (b) Mouse primary peritoneal macrophages were primed with LPS $(1 \mu \mathrm{g} / \mathrm{ml}, 2 \mathrm{~h})$, followed by treatment with TPEN $(10 \mu \mathrm{M}, 4 \mathrm{~h}) \pm 50 \mu \mathrm{M} \mathrm{ZnCl} 2$ with release of IL-1 $\beta$ measured by ELISA (i) and cell death by $\mathrm{LDH}$ release (ii). (c) Mouse primary peritoneal macrophages were primed with $\mathrm{LPS}(1 \mu \mathrm{g} / \mathrm{ml}, 2 \mathrm{~h})$, followed by $4 \mathrm{~h}$ treatment with the non-cell permeable $\mathrm{Zn}^{2+}$ chelator DTPA $\left(1 \mathrm{mM}\right.$ ) with release of IL-1 $\beta$ measured by ELISA. (d) $\mathrm{J} 774$ macrophages were loaded with the $\mathrm{Zn}^{2+}$ indicator FluoZin-3 and Lysotracker Red and then treated with $1 \mu \mathrm{M}$ of the $\mathrm{Zn}^{2+}$ ionophore, 1-hydroxypyridine-2-thione (zinc salt) (ZnPyr), to induce increases in cellular $\mathrm{Zn}^{2+}$. Addition of TPEN to a $\mathrm{Zn}^{2+}$-loaded cell caused a rapid drop in FluoZin-3 fluorescence. Shown are snap shot images taken with a BD Pathway illustrating the fluorescence changes over the course of the experiment. Scale bar $=50 \mu \mathrm{m}$. (e) Representative fluorescent traces (F/Fo) of FluoZin-3 (i) and lysotracker red (ii) of the experiment shown in d. All data are presented as the mean \pm S.D. from at least four separate experiments. Blots shown are representative. ${ }^{* \star *} P<0.001,{ }^{* \star} P<0.01,{ }^{\star} P<0.05$

DTPA and the $\mathrm{Zn}^{2+}$ ionophore pyrithione also induced a loss of XIAP and an activation of caspase-8 (Figure 3ai, ii). TPEN treatment also induced activation of caspase-1, as seen by the appearance of the active caspase- 1 subunit $(10 \mathrm{kDa})$ in
TPEN-treated culture supernatants (Figure 3aiii). This activation of caspase- 1 was inhibited by the addition of $1 \mu \mathrm{M} \mathrm{ZnPyr}$ confirming the $\mathrm{Zn}^{2+}$ dependence of this effect. Thus, from these data it is clear that $\mathrm{Zn}^{2+}$ depletion activated both 


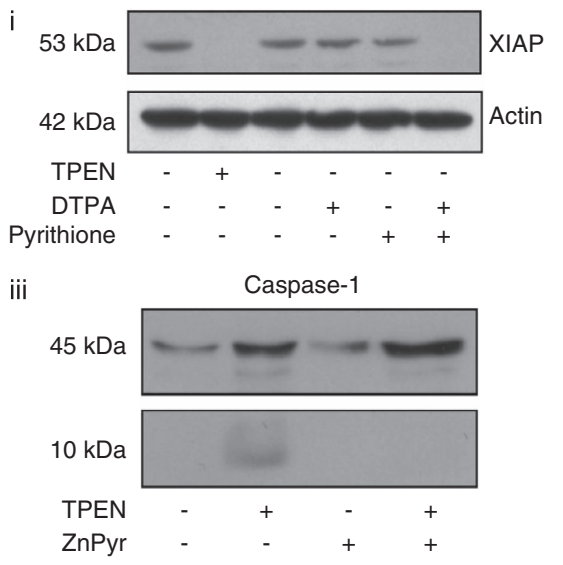

ii

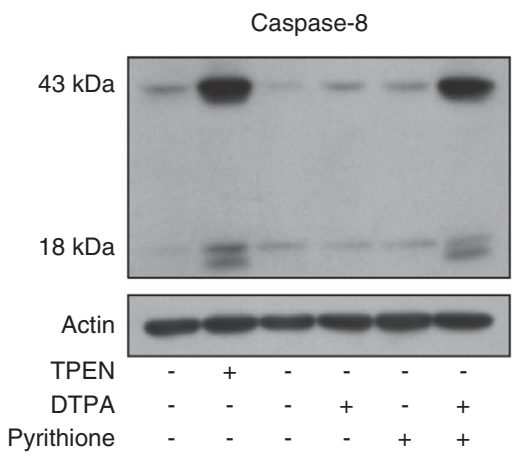

bi

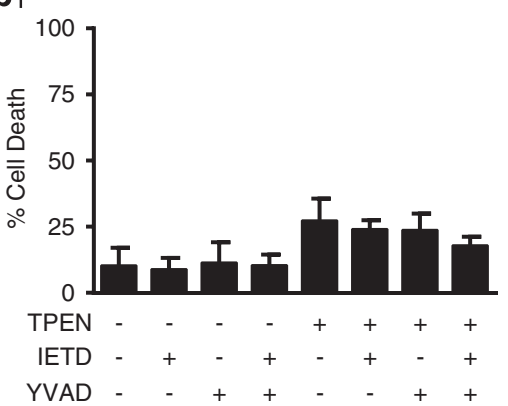

ii

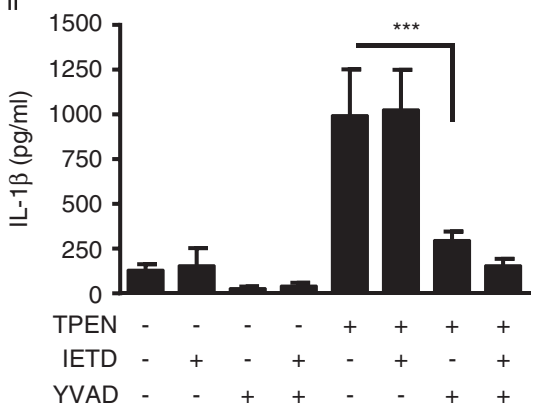

Figure 3 TPEN-induced IL-1 $\beta$ release is dependent upon caspase-1. (a) Lysates of mouse peritoneal macrophages treated with LPS $(1 \mu \mathrm{g} / \mathrm{ml}, 2 \mathrm{~h})$ and TPEN $(10 \mu \mathrm{M}$, $4 \mathrm{~h})$, or DTPA $(1 \mathrm{mM})$ and pyrithione $(50 \mu \mathrm{M})$, or TPEN $\pm 1 \mu \mathrm{M}$ of 1-hydroxypyridine-2-thione (zinc salt) (ZnPyr), were blotted for the house keeping protein actin (band at $42 \mathrm{kDa}$ ) and for XIAP (band at $53 \mathrm{kDa}$ ) (i). Lysates were also blotted for active caspase-8 sub-units (43 and $18 \mathrm{kDa}$ ) (ii), and for pro- (45 kDa) and active (10 kDa) caspase-1 (iii). (b) LPS-primed primary peritoneal macrophages were treated with TPEN $(10 \mu \mathrm{M}, 4 \mathrm{~h})$ plus and minus incubation with the caspase-1 inhibitor Ac-YVAD-CHO (100 $\mu \mathrm{M})$ or the caspase-8 inhibitor IETD-CHO $(100 \mu \mathrm{M})$ with cell death measured by LDH assay (i) and IL-1 $\beta$ release by ELISA (ii). All data are presented as the mean \pm S.D. from at least four separate experiments. Blots shown are representative. ${ }^{* \star} P<0.001$

caspase- 1 and caspase-8. To determine which of these caspases were involved in TPEN-induced IL-1 $\beta$ processing and release, we used selective caspase- 1 and caspase-8 inhibitors. The caspase-1 inhibitor Ac-YVAD-CHO or the caspase-8 inhibitor IETD-CHO had no effect on TPENinduced cell death (Figure 3bi). However, although IETD had no effect on TPEN-induced IL-1 $\beta$ secretion (Figure 3bii), incubation of TPEN-treated macrophages with YVAD resulted in inhibition of IL-1 $\beta$ release, suggesting that TPEN-induced IL-1 $\beta$ processing and release were caspase- 1 dependent (Figure 3bii). Thus, TPEN induced the activation of caspase-1, and the processing and release of IL-1 $\beta$, which was blocked by a selective caspase- 1 inhibitor.

Caspase- 1 activation is regulated by multi-protein complexes called inflammasomes. The NLRP3 inflammasome is generally regarded as a sensor of sterile injury, and given that TPEN is a sterile stimulus we hypothesised that TPENinduced IL-1 $\beta$ release occurred through activation of the NLRP3 inflammasome. We reported recently that PP1/PP2A phosphatase inhibitors such as calyculin $A(C A)$ and okadaic acid are potent inhibitors of multiple inflammasomes. ${ }^{23}$ Incubation of LPS-primed primary peritoneal macrophages with 10 or $50 \mathrm{nM}$ CA completely inhibited TPEN-induced $\mathrm{IL}-1 \beta$ processing and release (Figure $4 \mathrm{a}$ ), consistent with our previous observations on inflammasome inhibition. ${ }^{23}$ To test the involvement of NLRP3, we incubated LPS-primed peritoneal macrophages with the NLRP3 inflammasome inhibitor glyburide ${ }^{24}$ which also significantly inhibited TPENinduced IL-1 $\beta$ release (Figure $4 b$ ). When treated with TPEN, macrophages from NLRP3 KO mice secreted significantly less IL-1 $\beta$ compared with WT macrophages, although cell death responses were not affected (Figure 4c). Likewise, macrophages isolated from ASC KO mice also secreted significantly less IL-1 $\beta$ than WT in response to TPEN (Figure 4d). Together, these data strongly suggest that $\mathrm{Zn}^{2+}$ depletion activates the processing and secretion of IL- $1 \beta$, which is at least partially via a NLRP3-inflammasome/ caspase-1-dependent pathway.

Canonical NLRP3 inflammasome activation is reported to depend upon one, or a combination of signals that include $\mathrm{K}^{+}$ ion efflux, ${ }^{25}$ reactive oxygen species (ROS) generation, ${ }^{26}$ or destabilisation of lysosomal membranes. ${ }^{27}$ Destabilisation of lysosomal membranes and the release of cathepsins from the lysosome into the cytosol is reported to activate the NLRP3 inflammasome in response to DAMPs such as Alum and amyloid-beta $(\mathrm{A} \beta)$ and infection by certain pathogens (e.g., Listeria monocytogenes). ${ }^{27-29}$ Recently, $\mathrm{K}^{+}$efflux was linked to NLRP3 activation in response to DAMPs and reagents that 
a

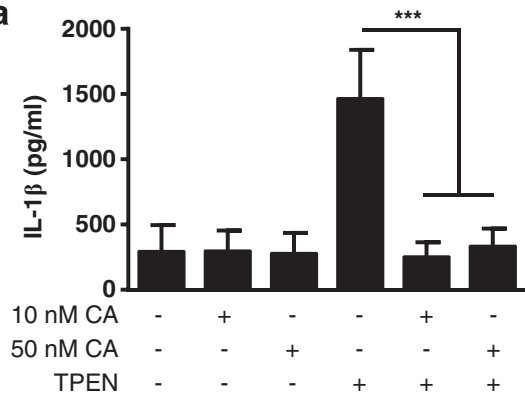

C i
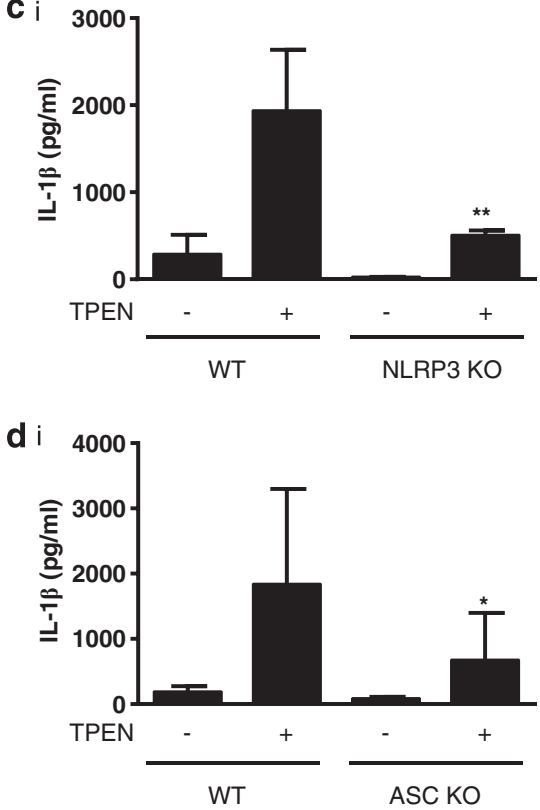

b
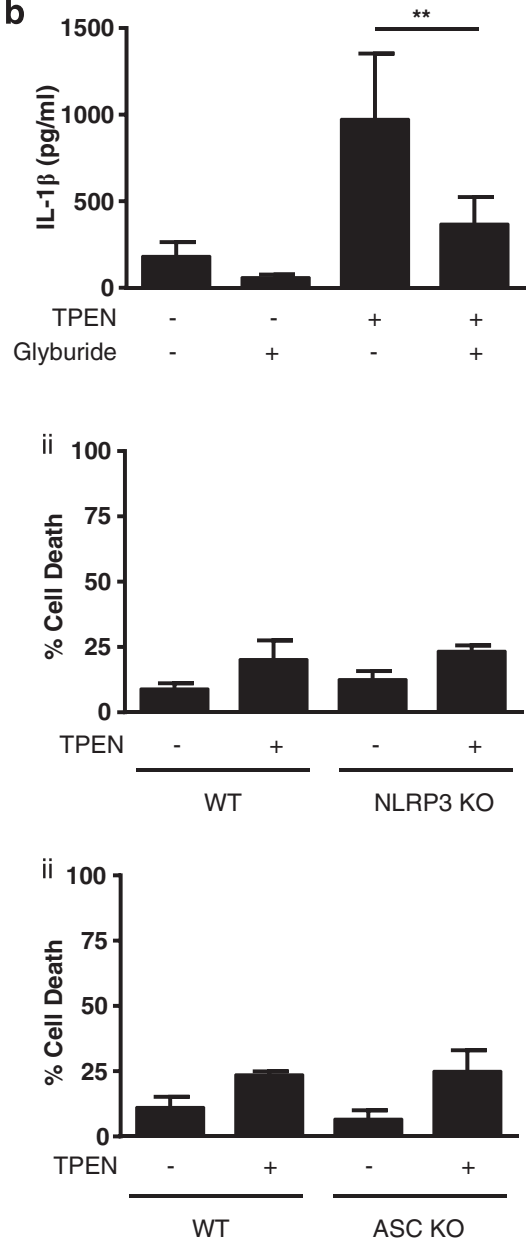

Figure 4 TPEN-induced IL-1 $\beta$ release is dependent upon the NLRP3 inflammasome. (a) LPS-primed primary peritoneal macrophages were incubated with CA (10 or $50 \mathrm{nM})$ followed by TPEN $(10 \mu \mathrm{M}, 4 \mathrm{~h})$ with IL-1 $\beta$ release measured by ELISA. (b) LPS-primed peritoneal macrophages were incubated with the NLRP3 inflammasome inhibitor glyburide $(100 \mu \mathrm{M})$ before incubation with TPEN $(10 \mu \mathrm{M}, 4 \mathrm{~h})$ with IL-1 $\beta$ release measured by ELISA. (c) Macrophages isolated from WT and NLRP3 KO mice were LPS-primed $(1 \mu \mathrm{g} / \mathrm{ml}, 2 \mathrm{~h})$ and then treated with TPEN $(10 \mu \mathrm{M}, 4 \mathrm{~h})$ with IL-1 $\beta$ release measured by ELISA (i), and cell death by LDH release (ii). (d) Macrophages isolated from WT and ASC KO mice were LPS-primed $(1 \mu \mathrm{g} / \mathrm{ml}, 2 \mathrm{~h})$ and then treated with TPEN $(10 \mu \mathrm{M}, 4 \mathrm{~h})$ with IL-1 $\beta$ release measured by ELISA (i), and cell death by LDH release (ii). All data are presented as the mean \pm S.D. from at least four separate experiments. ${ }^{* * *} P<0.001,{ }^{* *} P<0.01,{ }^{*} P<0.05$

also damage lysosomal membranes, perhaps identifying it as a general mechanism regulating inflammasome activation. ${ }^{30}$ We tested whether TPEN treatment of LPS-treated macrophages induced a ROS response. However, using the ROS indicator MitoSOX TPEN failed to induce a detectable increase in ROS, whereas sphingosine, a recently characterised activator of NLRP3, ${ }^{23}$ induced a robust increase (data not shown). Labile $\mathrm{Zn}^{2+}$, as detected with the fluorescence probe FluoZin-3, localises to lysosomes in $\mathrm{T}_{\text {cells }}{ }^{31}$ and in cultured neurones. ${ }^{32}$ We identified partial co-localisation between FluoZin-3 and the lysosome-specific dye lysotracker red in LPS-treated peritoneal macrophages (Figure 5a). Therefore, we tested whether TPEN-induced NLRP3 inflammasome activation and IL-1 $\beta$ secretion were dependent upon lysosomal destabilisation. First, we showed that incubation of primary peritoneal macrophages with the cathepsin $B$ inhibitor Ca-074-Me $(80 \mu \mathrm{M})$ resulted in an inhibition of TPEN-induced $\mathrm{IL}-1 \beta$ release (Figure $5 \mathrm{~b}$ ), suggesting that TPEN influenced lysosomal membrane stability. Furthermore, pre-treatment of LPS-primed macrophages with the vacuolar H1-ATPase inhibitor bafilomycin A caused a partial but significant inhibition of TPEN-induced IL-1 $\beta$ release, further suggesting that a loss of lysosomal integrity is important (Figure $5 \mathrm{~d}$ ). Neither TPEN nor A $\beta$ (previously reported to activate NLRP3 via lysosomal destabilisation ${ }^{28}$ ) increased cathepsin activity in peritoneal macrophage cell lysates (Figure 5c), further suggesting that lysosomal membrane disruption and a redistribution of lysosomal contents are required for TPENinduced IL-1 $\beta$ release. We loaded peritoneal macrophages with Lysotracker Red and then incubated them with DMSO $(0.5 \%$, Veh) or TPEN $(10 \mu \mathrm{M})$ for up to $4.5 \mathrm{~h}$. We then took 'snap-shot' images of the live cells using a BD Pathway Bioimager. The fluorescent DNA dye Hoechst was included in the culture media allowing labelling of cells in which plasma membrane integrity was compromised. Loss of Lysotracker red labelling correlated with an increase in Hoechst labelling in the TPEN-treated cells (Figure 5e). Lysosomal membrane permeabilisation is a well-characterised mechanism of cell death where release of cytotoxic cathepsins into the cytosol reduces cell viability. ${ }^{33}$ To further establish that $\mathrm{Zn}^{2+}$ 
a
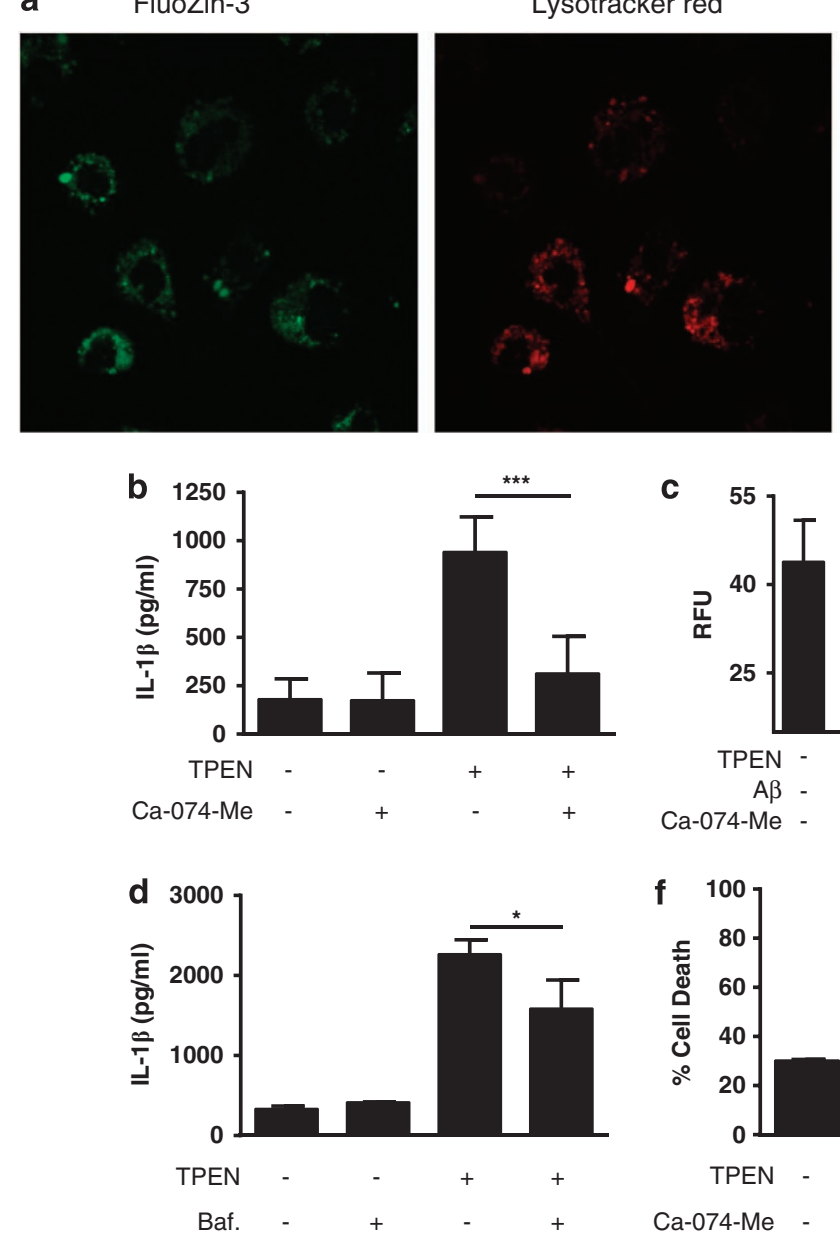

e

Veh
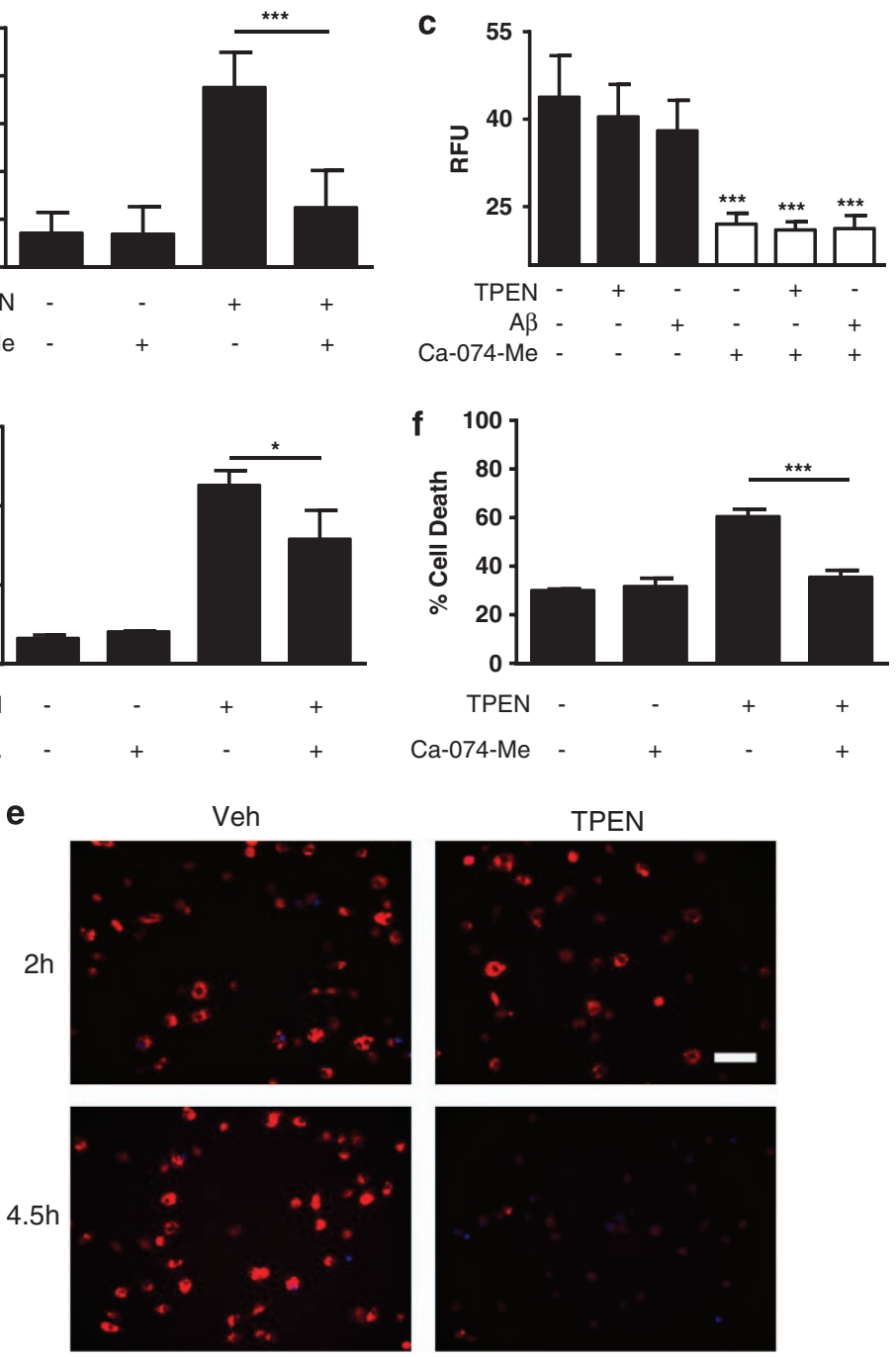

Figure 5 TPEN-induced NLRP3 inflammasome activation depends upon a loss of lysosomal integrity. (a) LPS-primed ( $1 \mu \mathrm{g} / \mathrm{ml}, 2 \mathrm{~h})$ peritoneal macrophages were loaded with FluoZin-3 and Lysotracker Red and imaged using a spinning disc confocal microscope. Scale bar represents $5 \mu \mathrm{m}$. (b) LPS-primed peritoneal macrophages were incubated with the cathepsin B inhibitor Ca-074-Me $(80 \mu \mathrm{M})$ before incubation with TPEN $(10 \mu \mathrm{M}, 4 \mathrm{~h})$ with IL-1 $\beta$ release measured by ELISA. (c) LPS-primed peritoneal macrophages were incubated with TPEN $(10 \mu \mathrm{M}, 4 \mathrm{~h})$ or $\mathrm{A} \beta(5 \mu \mathrm{M}, 4 \mathrm{~h})$ after which cells were lysed in hypotonic lysis buffer. Cathepsin $\mathrm{B} / \mathrm{L}$-dependent cleavage of the fluorogenic substrate Z-Phe-Arg-AMC $(40 \mu \mathrm{M})$ was measured by an increase in fluorescence (excitation $335 \mathrm{~nm}$, emission $460 \mathrm{~nm})$. The cathepsin B inhibitor Ca-074-Me $(100 \mu \mathrm{M})$ was included as a control. (d) LPS-primed peritoneal macrophages were incubated with bafilomycin A (100 nM) before incubation with TPEN (10 $\mu \mathrm{M}, 4 \mathrm{~h})$ with IL-1 $\beta$ release measured by ELISA. (e) LPS-primed $(1 \mu \mathrm{g} / \mathrm{ml}, 2 \mathrm{~h}$ ) peritoneal macrophages were loaded with Lysotracker Red and then incubated with DMSO (0.5\%, Veh), or TPEN $(10 \mu \mathrm{M})$ for 2 and $4.5 \mathrm{~h}$. Snap shot images of live cells were taken using a BD Pathway Bioimager. Hoechst was included in the culture media allowing labelling of cells in which plasma membrane integrity was compromised. Scale bar $=50 \mu \mathrm{m}$. (f) LPS-primed peritoneal macrophages were incubated with TPEN $(10 \mu \mathrm{M}, 6 \mathrm{~h})$ plus and minus Ca-074$\mathrm{Me}(100 \mu \mathrm{M})$ with cell death measured by release of LDH. All data are presented as the mean \pm S.D. from at least four separate experiments. All images are representative. ${ }^{* * *} P<0.001,{ }^{*} P<0.05$ 
depletion was inducing this effect, we investigated whether the cathepsin B inhibitor Ca-074-Me reduced TPEN-induced cell death. LPS-primed peritoneal macrophages were incubated with TPEN $(10 \mu \mathrm{M})$ for the slightly longer time of $6 \mathrm{~h}$ (to induce a robust cell death response) plus and minus $\mathrm{Ca}-074-$ $\mathrm{Me}(100 \mu \mathrm{M})$ with cell death measured by release of lactate dehydrogenase (LDH). Ca-074-Me was protective against TPEN-induced cell death (Figure 5f). Thus, from these data we conclude that $\mathrm{Zn}^{2+}$ depletion induces inflammasome activation and cell death via a disruption of lysosomal integrity. Even though both caspases 1 and 8 were activated by TPEN, neither a caspase-8 nor a caspase- 1 inhibitor reduced TPENinduced cell death (Figure 3). NLRP3 KO macrophages also released comparable levels of LDH compared with WT macrophages in response to TPEN (Figure 4). These data suggest that pyroptosis is probably not the mechanism of cell death we observe, and the rapid onset of membrane permeabilisation (4-6h) suggests that the death is not apoptotic. Our data suggest that the mechanism of TPENinduced cell death is lysosomal in nature. Lysosomal damage is known to contribute to multiple cell death paradigms, ${ }^{33}$ and lysosomal protease-dependent cell death, in the presence of active caspases, has been reported previously (e.g., see $\mathrm{Di}$ Piazza et $a .^{34}$ and Nylandsted et $a l^{35}$ ).

The molecular sensors for $\mathrm{Zn}^{2+}$ in this system are unknown. Approximately 2800 proteins are known to bind $\mathrm{Zn}^{2+},{ }^{7}$ and the effect we observe here could be due to either a direct or an indirect effect of the function, or loss of function, of one or many of these proteins. Given the importance of intracellular $\mathrm{Zn}^{2+}$, it is expected that a drop in its levels would elicit a prototypical response to danger; namely the secretion of $\mathrm{IL}-1 \beta$. There is also literature reporting the direct stabilising effects of $\mathrm{Zn}^{2+}$ on biological membranes, and in particular lysosomal membranes. $^{36,37}$ Thus, the effects of $\mathrm{Zn}^{2+}$ depletion on lysosomal membranes could depend upon multiple factors.

Given its prevalence and association with inflammation and disease, $\mathrm{Zn}^{2+}$ deficiency potentially represents a major comorbidity for disease. Rodents fed $\mathrm{Zn}^{2+}$-deficient diets suffer exacerbated pathology in models of colitis ${ }^{38}$ and polymicrobial sepsis. ${ }^{39}$ Humans with Alzheimer's disease (AD) are also $\mathrm{Zn}^{2+}$ deficient. ${ }^{40,41}$ In this respect, $\mathrm{AD}$ is particularly interesting as we know that aggregated $\mathrm{A} \beta$, a pathological feature of $A D$, induces NLRP3 inflammasome activation via a mechanism dependent upon destabilisation of lysosomes and cathepsin $B .^{28}$ The memory deficits that occur in the APP/PS1 mouse model of AD also appear to be entirely dependent upon the NLRP3 inflammasome. ${ }^{42}$ In a negative feedback loop, $\mathrm{Zn}^{2+}$ inhibits NF- $\mathrm{kB}$-dependent inflammation via the $\mathrm{Zn}^{2+}$ transporter ZIP8, itself regulated by NF- $\kappa B$, and does this via an inhibition of $I_{\kappa} B$ kinase. ${ }^{43}$ Under conditions of $\mathrm{Zn}^{2+}$ deficiency Liu et al. ${ }^{43}$ report excessive inflammation in a model of sepsis as a result of losing this negative feedback. Thus, in addition to the mechanism reported by Liu et al., ${ }^{43}$ we have identified that activation of the NLRP3 inflammasome can also contribute to inflammation under conditions of $\mathrm{Zn}^{2+}$ deficiency, and that this is likely via a direct effect on lysosomal membrane integrity. These data therefore suggest that $\mathrm{Zn}^{2+}$ deficiency could be a contributor to disease in which there is an IL-1 $\beta$-dependent inflammatory response. $\mathrm{Zn}^{2+}$ deficiency is easily resolved using dietary
$\mathrm{Zn}^{2+}$ supplements, ${ }^{13,14}$ and this could potentially represent a simple treatment for inflammatory disease where plasma $\mathrm{Zn}^{2}+$ levels are found to be low.

\section{Materials and Methods}

Materials. RPMI 1640 and DMEM culture media, fetal bovine serum, glutamine, and a streptomycin/penicillin antibiotic solution were all purchased from Invitrogen (Paisley, UK). Bacterial LPS (Escherisha coli 026:B6), ZnPyr (zinc salt), TTM, TPEN, DTPA, pyrithione, CA, glyburide, and bafilomycin were purchased from Sigma (Gillingham, UK). Ac-YVAD-CHO, IETD-CHO, and Ca-074-Me were purchased from Merck Chemicals Ltd (Darmstadt, Germany). Salicylaldehyde isonicotinoyl hydrazone $(\mathrm{SIH})$ was purchased from ChemBridge (San Diego, CA, USA). FluoZin-3 and Lysotracker Red were purchased from Invitrogen. The anti-mouse IL- $1 \beta$ antibody was from R\&D Systems (Abingdon, UK). The XIAP and caspase-8 antibodies were purchased from Cell Signalling (Danvers, MA, USA), the actin antibody was from Sigma, and the caspase- 1 antibody was from Santa Cruz Biotechnology (Dallas, TX, USA). $\mathrm{A} \beta$ peptide (1-42) was purchased from rPeptide (Bogart, GA, USA).

Mice. NLRP3 and ASC KO mice were generously provided by Dr. Vishva Dixit, Genentech. ${ }^{44,45}$ C57BL/6J mice were purchased from Harlan (Blackthorn, UK).

In vivo sepsis. All procedures on animals conformed to the requirements of the UK Animal (Scientific Procedures) Act, 1986. Male C57BL/6 mice $(25-30 \mathrm{~g}$ bodyweight) were injected i.p. with a septic dose of LPS (E. coli 0127:B8, Sigma, $5 \mathrm{mg} / \mathrm{kg}$ ) prepared in sterile $0.9 \%$ saline. $1 \mathrm{~h}$ after LPS injection the mice received a second injection that was vehicle (10\% DMSO in saline), $1 \mathrm{mg} / \mathrm{kg}$ TPEN, or $10 \mathrm{mg} / \mathrm{kg}$ TPEN. $3 \mathrm{~h}$ after the second injection the animals were terminally anaesthetised with $3 \%$ isoflurane, lavage fluid was collected, and blood collected via cardiac puncture. Samples were centrifuged and supernatants collected and frozen until analysis.

Cell culture. Primary peritoneal macrophages were prepared from adult, male C57BL/6 mice, as described previously. ${ }^{46}$ Peritoneal macrophages were cultured at a density of $5 \times 10^{5}$ cells/well in RPMl 1640 media supplemented with $5 \%$ FCS, $100 \mathrm{U} / \mathrm{ml}$ penicillin and $100 \mu \mathrm{g} / \mathrm{ml}$ streptomycin. $24 \mathrm{~h}$ after culture cells were treated with LPS $(1 \mu \mathrm{g} / \mathrm{ml}, 2 \mathrm{~h})$ before a $4 \mathrm{~h}$ incubation with $10 \mu \mathrm{M}$ TPEN (or other treatments where indicated). Supernatants and lysates were harvested for subsequent analyses. For the imaging experiments, primary peritoneal macrophages or J774 macrophages were treated with LPS $(1 \mu \mathrm{g} / \mathrm{ml}, 2 / 4 \mathrm{~h})$ and then loaded with FluoZin-3 and Lysotracker Red (see below).

\section{Imaging experiments}

FluoZin-3 and Lysotracker Red imaging: LPS-treated J774 macrophages were incubated with $10 \mu \mathrm{M}$ FluoZin-3 ester plus $0.02 \%$ pluronic acid and $100 \mathrm{nM}$ Lysotracker Red for $30 \mathrm{~min}$. After incubation, cells were washed three times with media to remove excess dye and were then imaged.

Co-localisation of FluoZin-3 and Lysotracker Red was observed using a Zeiss Axio-Observer Z1 microscope equipped with a CSU-X1 spinning disc confocal microscope (Yokagowa, Tokyo, Japan) and imaged using an Evolve EM CCD camera (Photometrics, Tucson, AZ, USA). Live cell kinetics of $\mathrm{Zn}^{2+}$ loading was performed using a BD Pathway Bioimager with liquid handling (see below). All offline analysis of images and movies used ImageJ software (http://rsb.info.nih.gov/ij/). In ImageJ, cells were selected as regions of interest (ROI) and at least 15 cells per field of view were analysed. The fluorescence $(F)$ data are expressed as a fluorescence change relative to the initial baseline fluorescence value (Fo).

Lysotracker Red and Hoechst imaging: LPS-treated peritoneal macrophages $(2 \mathrm{~h}, 1 \mu \mathrm{g} / \mathrm{ml})$ were incubated with Lysotracker Red $(100 \mathrm{nM})$ for $30 \mathrm{~min}$. Cells were washed three times and incubated with media containing $2 \mu \mathrm{g} / \mathrm{ml}$ Hoechst plus either vehicle $(0.5 \%$ DMSO) or TPEN $(10 \mu \mathrm{M})$. Cells were then imaged at regular intervals up to $4.5 \mathrm{~h}$. For longer incubations $(>2 \mathrm{~h})$, cells were reloaded with Lysotracker for $30 \mathrm{~min}$ before imaging. Images were acquired on a Pathway Bioimager 855 (BD, Oxford, UK) with laser autofocus using a $\times 20 / 0.75$ Olympus objective (Southend, UK) and the following filtre setups: FluoZin-3 Ex. 334/10 Di. FURA/FITC Em. 520; Rhodamine Ex. 555/28 Di. FURA/FITC Em. 645/75; Hoechst Ex. 380/10 Di. FURA/TRITC Em. 520. For snap shot images, settings were determined manually. The BD Pathway and the spinning disc confocal microscopes are part of the Core Bioimaging Facility at the Faculty of Life 
Sciences, University of Manchester (http://www.Is.manchester.ac.uk/research/ facilities/bioimaging/)

Western blotting. Supernatants and lysates were harvested and prepared in sample buffer containing $1 \% \beta$-mercaptoethanol. Samples were boiled and then electrophoresed on 12\% SDS-acrylamide gels. For the caspase-1 blots, supernatants were concentrated using Amicon Ultra centrifugal filtres (Millipore, Darmstadt, Germany). Proteins were transferred to a nitrocellulose membrane and blotted with primary antibodies, followed by HRP-conjugated secondary antibodies, and subsequent exposure using enhanced chemi-luminesence reagents (ECL, Amersham, UK).

Detection of IL-1 $\beta$ and IL- 6 by ELISA. Measurement of IL- $1 \beta$ released into macrophage culture supernatants and peritoneal lavage fluid, and measurement of IL- 6 in lavage fluid, was done using specific mouse IL-1 $\beta$ and IL-6 ELISA kits (R\&D Systems) following manufacturer's instructions.

Cathepsin $B / L$ assay. Cells were lysed in hypotonic lysis buffer $(25 \mathrm{mM}$ HEPES, $5 \mathrm{mM}$ EGTA, $5 \mathrm{mM}$ DTT, pH 7.5) on ice, and lysates were mixed with $2 \times$ reaction buffer ( $0.2 \mathrm{M}$ sodium acetate buffer, $4 \mathrm{mM}$ EDTA, $4 \mathrm{mM}$ DTT, pH5.5). Cathepsin B/L-dependent cleavage of the fluorogenic substrate Z-Phe-Arg-AMC $(40 \mu \mathrm{M})$ was measured by an increase in fluorescence (excitation $335 \mathrm{~nm}$, emission $460 \mathrm{~nm}$ ). Data are expressed as relative fluorescence units.

Lactate dehydrogenase assay. Cell death was recorded by measuring the release of the enzyme LDH from the cells using the CytoTox-96 assay (Promega, Southampton, UK) according to manufacturer's instructions.

Data analysis. Cell culture data are presented as the mean \pm S.D. of at least three separate cultures. Groups of data were analysed by one-way ANOVA followed by Bonferroni's multiple comparison test. Statistical significance was assumed when $P<0.05$. All western blots presented are representative of three independent experiments from three separate cultures. The in vivo experiment used six animals per group.

\section{Conflict of Interest}

The authors decalre no conflict of interest.

Acknowledgements. We are grateful to Professor Vishva Dixit of Genentech for supplying the NLRP3 and ASC KO mice and to Professor Nancy Rothwell (Manchester) for critical feedback of the draft manuscript. We are also grateful to Dr. Peter March of the Biolmaging core facility at the University of Manchester for his help with the imaging experiments. This work was funded by the Wellcome Trust fellowship and the BBSRC. We also gratefully acknowledge the Post Thesis Submission Support Fund of the Faculty of Life Sciences (HS).

1. Rock KL, Latz E, Ontiveros $\mathrm{F}$, Kono $\mathrm{H}$. The sterile inflammatory response. Annu Rev Immunol 2010; 28: 321-342.

2. Dinarello CA, Simon A, van der Meer JW. Treating inflammation by blocking interleukin-1 in a broad spectrum of diseases. Nat Rev Drug Discov 2012; 11: 633-652.

3. Chen GY, Nunez G. Sterile inflammation: sensing and reacting to damage. Nat Rev Immunol 2010; 10: 826-837.

4. Takeuchi O, Akira S. Pattern recognition receptors and inflammation. Cell 2010; 140: 805-820.

5. Schroder K, Tschopp J. The inflammasomes. Cell 2010; 140: 821-832.

6. Cassel SL, Sutterwala FS. Sterile inflammatory responses mediated by the NLRP3 inflammasome. Eur J Immunol 2010; 40: 607-611.

7. Andreini C, Banci L, Bertini I, Rosato A. Counting the zinc-proteins encoded in the human genome. J Proteome Res 2006; 5: 196-201.

8. Haase H, Rink L. Functional Significance of Zinc-Related Signaling Pathways in Immune Cells. Annu Rev Nutr 2009; 29: 133-152.

9. Cousins RJ, Leinart AS. Tissue-specific regulation of zinc metabolism and metallothionein genes by interleukin 1. Faseb J 1988; 2: 2884-2890.

10. Gaetke LM, McClain CJ, Talwalkar RT, Shedlofsky SI. Effects of endotoxin on zinc metabolism in human volunteers. Am J Physiol 1997; 272: E952-E956.

11. Vasto S, Mocchegiani E, Candore G, Listi F, Colonna-Romano G, Lio D et al. Inflammation, genes and zinc in ageing and age-related diseases. Biogerontology 2006; 7: 315-327.

12. Prasad AS. Impact of the discovery of human zinc deficiency on health. J Am Coll Nutr 2009; 28: 257-265
13. Prasad AS. Zinc deficiency. Brit Med J 2003; 326: 409-410.

14. Prasad AS. Zinc: role in immunity, oxidative stress and chronic inflammation. Curr Opin Clin Nutr 2009; 12: 646-652.

15. Brough D, Pelegrin $P$, Rothwell NJ. Pannexin-1-dependent caspase-1 activation and secretion of IL-1beta is regulated by zinc. Eur J Immunol 2009; 39: 352-358.

16. Hornung V, Latz E. Critical functions of priming and lysosomal damage for NLRP3 activation. Eur J Immunol 2010; 40: 620-623.

17. Yamasaki S, Sakata-Sogawa K, Hasegawa A, Suzuki T, Kabu K, Sato E et al. Zinc is a novel intracellular second messenger. J Cell Biol 2007; 177: 637-645.

18. Makhov P, Golovine K, Uzzo RG, Rothman J, Crispen PL, Shaw $T$ et al. Zinc chelation induces rapid depletion of the $\mathrm{X}$-linked inhibitor of apoptosis and sensitizes prostate cancer cells to TRAIL-mediated apoptosis. Cell Death Differ 2008; 15: $1745-1751$.

19. Zuo J, Schmitt SM, Zhang Z, Prakash J, Fan Y, Bi C et al. Novel polypyridyl chelators deplete cellular zinc and destabilize the $X$-linked inhibitor of apoptosis protein (XIAP) prior to induction of apoptosis in human prostate and breast cancer cells. J Cell Biochem 2012; 113: 2567-2575.

20. Vince JE, Wong WW, Gentle I, Lawlor KE, Allam R, O'Reilly L et al. Inhibitor of apoptosis proteins limit RIP3 kinase-dependent interleukin-1 activation. Immunity 2012; 36 215-227.

21. Maelfait J, Vercammen E, Janssens S, Schotte P, Haegman M, Magez S et al. Stimulation of Toll-like receptor 3 and 4 induces interleukin-1 beta maturation by caspase-8. J Exp Med 2008; 205: 1967-1973.

22. Bossaller L, Chiang PI, Schmidt-Lauber C, Ganesan S, Kaiser WJ, Rathinam VA et al. Cutting Edge: FAS (CD95) mediates noncanonical IL-1beta and IL-18 maturation via caspase-8 in an RIP3-independent manner. J Immunol 2012; 189: 5508-5512.

23. Luheshi NM, Giles JA, Lopez-Castejon G, Brough D. Sphingosine regulates the NLRP3inflammasome and IL-1beta release from macrophages. Eur J Immunol 2012; 42: 716-725.

24. Lamkanfi M, Mueller JL, Vitari AC, Misaghi S, Fedorova A, Deshayes K et al. Glyburide inhibits the Cryopyrin/Nalp3 inflammasome. J Cell Biol 2009; 187: 61-70.

25. Petrilli V, Papin S, Dostert C, Mayor A, Martinon F, Tschopp J. Activation of the NALP3 inflammasome is triggered by low intracellular potassium concentration. Cell Death Differ 2007; 14: 1583-1589.

26. Martinon F. Signaling by ROS drives inflammasome activation. Eur J Immunol 2010; 40: 616-619.

27. Hornung V, Bauernfeind F, Halle A, Samstad EO, Kono H, Rock KL et al. Silica crystals and aluminum salts activate the NALP3 inflammasome through phagosomal destabilization. Nat Immunol 2008; 9: 847-856.

28. Halle A, Hornung V, Petzold GC, Stewart CR, Monks BG, Reinheckel T et al. The NALP3 inflammasome is involved in the innate immune response to amyloid-beta. Nat Immunol 2008; 9: 857-865.

29. Meixenberger K, Pache F, Eitel J, Schmeck B, Hippenstiel S, Slevogt H et al. Listeria monocytogenes-infected human peripheral blood mononuclear cells produce IL-1beta, depending on listeriolysin 0 and NLRP3. J Immunol 2010; 184: 922-930.

30. Munoz-Planillo R, Kuffa P, Martinez-Colon G, Smith BL, Rajendiran TM, Nunez G. K(+) efflux is the common trigger of NLRP3 inflammasome activation by bacterial toxins and particulate matter. Immunity 2013; 38: 1142-1153.

31. Aydemir TB, Liuzzi JP, McClellan S, Cousins RJ. Zinc transporter ZIP8 (SLC39A8) and zinc influence IFN-gamma expression in activated human T cells. J Leukocyte Biol 2009 86: $337-348$.

32. Hwang JJ, Lee SJ, Kim TY, Cho JH, Koh JY. Zinc and 4-hydroxy-2-nonenal mediate lysosomal membrane permeabilization induced by $\mathrm{H} 2 \mathrm{O} 2$ in cultured hippocampal neurons. J Neurosci 2008; 28: 3114-3122.

33. Aits S, Jaattela M. Lysosomal cell death at a glance. J Cell Sci 2013; 126: 1905-1912.

34. Di Piazza M, Mader C, Geletneky K, Herrero YCM, Weber E, Schlehofer J et al. Cytosolic activation of cathepsins mediates parvovirus $\mathrm{H}$-1-induced killing of cisplatin and TRAlL-resistant glioma cells. J Virol 2007; 81: 4186-4198.

35. Nylandsted J, Gyrd-Hansen M, Danielewicz A, Fehrenbacher N, Lademann U, Hoyer-Hansen $\mathrm{M}$ et al. Heat shock protein 70 promotes cell survival by inhibiting lysosomal membrane permeabilization. J Exp Med 2004; 200: 425-435.

36. Chvapil M, Ryan JN, Brada Z. Effects of selected chelating agents and metals on the stability of liver lysosomes. Biochem Pharmacol 1972; 21: 1097-1105.

37. Ludwig JC, Chvapil M. Reversible stabilization of liver lysosomes by zinc ions. J Nutr 1980; 110: 945-953.

38. Iwaya $\mathrm{H}$, Kashiwaya $\mathrm{M}$, Shinoki A, Lee JS, Hayashi $\mathrm{K}$, Hara $\mathrm{H}$ et al. Marginal zinc deficiency exacerbates experimental colitis induced by dextran sulfate sodium in rats. J Nutr 2011; 141: 1077-1082.

39. Knoell DL, Julian MW, Bao S, Besecker B, Macre JE, Leikauf GD et al. Zinc deficiency increases organ damage and mortality in a murine model of polymicrobial sepsis. Criti Care Med 2009; 37: 1380-1388.

40. Brewer GJ, Kanzer SH, Zimmerman EA, Molho ES, Celmins DF, Heckman SM et al. Subclinical zinc deficiency in Alzheimer's disease and Parkinson's disease. Am J Alzheimer's Dis Other Demen 2010; 25: 572-575.

41. Doecke JD, Laws SM, Faux NG, Wilson W, Burnham SC, Lam CP et al. Blood-based protein biomarkers for diagnosis of Alzheimer disease. Arch Neurol-Chicago 2012; 69: 1318-1325. 
42. Heneka MT, Kummer MP, Stutz A, Delekate A, Schwartz S, Vieira-Saecker A et al. NLRP3 is activated in Alzheimer's disease and contributes to pathology in APP/PS1 mice. Nature 2013; 493: 674-678.

43. Liu MJ, Bao S, Galvez-Peralta M, Pyle CJ, Rudawsky AC, Pavlovicz RE et al. ZIP8 Regulates Host Defense through Zinc-Mediated Inhibition of NF-kappaB. Cell Rep 2013; 3: 386-400

44. Mariathasan S, Newton K, Monack DM, Vucic D, French DM, Lee WP et al. Differential activation of the inflammasome by caspase-1 adaptors ASC and Ipaf. Nature 2004; 430: 213-218.

45. Mariathasan S, Weiss DS, Newton K, McBride J, O'Rourke K, Roose-Girma M et al. Cryopyrin activates the inflammasome in response to toxins and ATP. Nature 2006; 440 : 228-232.
46. Le Feuvre RA, Brough D, Iwakura Y, Takeda K, Rothwell NJ. Priming of macrophages with lipopolysaccharide potentiates P2 $\times 7$-mediated cell death via a caspase-1dependent mechanism, independently of cytokine production. J Biol Chem 2002; 277: 3210-3218.

(c) (i) Cell Death and Disease is an open-access journal published by Nature Publishing Group. This work is licensed under a Creative Commons Attribution 3.0 Unported License. To view a copy of this license, visit http://creativecommons.org/ licenses/by/3.0/ 